\title{
Ueber Toluylenharnstoff;
}

von Demselben.

Aehnlich wie das cyansaure Ammoniak sich isomer in Harnstoff umwandeln läfst, kann man bekanntlich auch die cyansauren Salze vieler Ammoniakbasen in sogenannte zusammengesetzte Harnstoffe verwandeln, d. h. in Carbamid, worin ein oder mehrere Wasserstoffatome durch Alkoholradicale vertreten sind. Während nun aber von den Monaminen grofsentheils schon die Harnstoffe bekannt sind,' sind von den Harnstoffen der Diaminbasen bis jetzt nur wenige, hauptsächlich die der Aethylendiamine, dargestellt worden.

Es schien daher nicht ganz ohne Interesse, andere Basen in dieser Beziehung einer näheren Prüfung zu unterwerfen. Ich wăhlte hierzu das Toluylendiamin, wovon mir Herr Prof. Strecker eine gewisse Menge zur Disposition stellte. Da ich beabsichtigte, den Toluylenharnstoff durch die Reaction des schwefelsauren Salzes mit cyansaurem Kali darzustellen, so mufste ich mir zunãchst ersteres Salz darstellen, welches bis jetzt noch nicht beschrieben ist. Es wird leicht auf $\mathrm{Zu}-$ satz von verdünnter Schwefelsäure zu einer concentrirten heifsen Lösung von Toluylendiamin in Wasser erhalten, indem es sich beim Erkalten in Jangen, sehr hübsch ausgebildeten monoklinometrischen Säulen abscheidet. Die vollkommen durchsichtigen, etwas gelb gefärbten Krystalle zeigen starke Doppelbrechung.

Das luftbeständige Salz verlor bei $100^{\circ} 8,5 \mathrm{pC}$. Wasser, und enthielt hierauf $36,9 \mathrm{pC}$. Schwefelsăure, welche Resultate der Formel : $\mathrm{G}_{7} \mathrm{H}_{10} \mathrm{~N}_{2} \cdot \mathrm{H}_{2} \mathrm{~S} \theta_{4}+2$ aq. entsprechen, wonach 7,9 pC. Krystallwasser und im trockenen Salz $36,6 \mathrm{pC}$. Schwefelsäure darin enthalten sind.

Eine warme wässerige Lösung dieses Salzes fügte ich 
allmälig zu einer in Eis abgekühlten Lösung von cyansaurem Kali, in dem Verhältnifs von einem Molecul des ersteren Salzes zu zwei Moleculen des letzteren. Es fand hierbei nur eine geringe Kohlensäureentwickelung statt, dagegen trübte sich die Anfangs klare Mischung nach einigen Minuten durch Abscheidung eines pulverförmigen Körpers. Die ganze Masse wurde im Wasserbad zur Trockne verdampft und der Rũckstand mit Weingeist ausgezogen.

Der in Weingeist unlösliche Rückstand enthielt neben schwefelsaurem Kali einen in Wasser sehr schwerlöslichen Körper, den ich nach Entfernung des schwefelsauren Kali's durch lauwarmes Wasser im Rückstand behielt.

Ich lōste denselben nun in kochendem Wasser, entfärbte noch mit etwas Thierkohle, und überliefs die heifs gesättigte Lōsung der Krystallisation.

Nach einigen Minuten schied sich derselbe in glimmerartig glänzenden Krystallen ab; aus einer schwächer gesättigten Lösung erhielt ich ihn in hübschen Nadeln krystallisirt. Was die Löslichkeit dieses Körpers anlangt, so habe ich oben angeführt, dafs er in Wasser sehr schwer loslich ist; in Weingeist löst er sich, selbst in der Siedehitze, auch nur wenig. Er schmilzt bei $220^{\circ} \mathrm{C}$. Die Verbrennung mit chromsaurem Bleioxyd mit vorgelegtem Kupfer gab :

I. 0,2285 Grm. Substanz gaben $0,4386 \theta_{2}$ und $0,12 \mathrm{H}_{2} \theta$.

II. $0,286 \mathrm{Grm}$. Substanz gaben $0,556 \theta_{2}$ und $0,159 \mathrm{H}_{2} \theta$.

III. $0,2225 \mathrm{Grm}$. Substanz gaben $0,4245 \mathrm{G}_{2}$ und $0,126 \mathrm{H}_{2} \theta$.

Die Stickstoffbestimmung nach Will gab :

IV. 0,2030 Grm. Substanz gaben 0,389 Platin.

In Procenten :

\begin{tabular}{|c|c|c|c|c|c|}
\hline \multirow{2}{*}{\multicolumn{2}{|c|}{$\begin{array}{l}\text { Berechnet } \\
\boldsymbol{G}_{9} \mathrm{H}_{12} \mathrm{~N}_{4} \theta_{2}\end{array}$}} & \multicolumn{4}{|c|}{ Gefunden } \\
\hline & & \multirow{2}{*}{$\begin{array}{c}\text { I. } \\
52,2\end{array}$} & \multirow{2}{*}{$\begin{array}{l}\text { II. } \\
52,4\end{array}$} & \multirow{2}{*}{$\begin{array}{l}\text { III. } \\
52,0\end{array}$} & \multirow{2}{*}{$\begin{array}{l}\text { IV. } \\
-\end{array}$} \\
\hline $\boldsymbol{G}$ & 51,9 & & & & \\
\hline $\mathbf{H}$ & 5,8 & 5,8 & 6,1 & 6,2 & - \\
\hline $\mathbf{N}$ & 26,9 & - & - & - & 27,1 \\
\hline
\end{tabular}


Der Toluylenharnstoff besitzt entschieden basische Eigenschaften : er löst sich in Salzsäure und Salpetersåure leicht auf, aber nach kurzer Zeit scheidet sich das salzsaure oder salpetersaure Salz krystallinisch ab. Auch mit Platinchlorid bildet er ein in Wasser, Alkohol und Aether lösliches Doppelsalz.

Von den Salzen dieses Harnstoffs habe ich nur das salzsaure nãher untersucht. Ich stellte die Verbindung dadurch dar, dafs ich über den Harnstoff in einem Liebig'schen Trockenapparate durch Sclıwefelsäure getrocknetes Salzsäuregas so lange leitete, als noch eine Aufnahme stattfand. Die Menge der aufgenommenen Salzsăure $(33,8 \mathrm{pC}$.) entspricht $2 \mathrm{HCl}$ (berechnet $35,0 \mathrm{pC}$ ), so dafs das Salz die Formel $\mathrm{G}_{9} \mathrm{H}_{12} \mathrm{~N}_{4} \mathrm{O}_{2}+2 \mathrm{HCl}$ besitzt.

Wird der Harnsloff über seinen Schmelzpunkt erhitzt, so entwickelt sich Ammoniak, und es bildet sich ein weifses Sublimat von Toluylendiamin, während Cyanursäure im Rückstand bleibt.

Aber aufser diesem Harnstoff tritt zugleich noch ein zweiler Kōrper auf, der ebenfalls die Fähigkeit hat, zu krystallisiren, und sich wesentlich durch seine leichte Löslichkeit in Weingeist von dem anderen unterscheidet. Da die Menge dieses Körpers höchst unbedeutend war, so war es mir blofs möglich, eine Stickstoffbestimmung desselben zu machen, die mich zu folgendem Resultate führte.

0,209 Grm. Substanz gaben nach dem Verbrennen mit Natronkalk 0,3635 Platin, entsprechend 24,6 pC. Stickstoff.

Diese Bestimmung macht es wahrscheinlich, dafs der untersuchte Körper mit dem schon früher von Herrn Märker im hiesigen Laboratorium dargestellten, dem einfach-cyansauren Toluylendiamin isomeren Harnstoff identisch ist, dessen Formel 25,4 pC. Stickstoff verlangt. 
Dem von mir dargestellten Toluylenharnstoff kommt folgende Constitutionsformel zu :<smiles>CCCCC(NOC(N)=O)NC(N)=O</smiles>

während der von Märker schon dargestellte Harnstoff die Formel

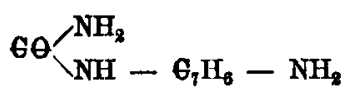

hat. Der erstere entsteht aus dem zweifach-cyansauren Toluylendiamin, während sich der letztere aus dem einfachsauren Salz dieser Base bildet :

$$
\begin{aligned}
& \mathbf{G}_{7} \mathrm{H}_{10} \mathbf{N}_{\mathbf{2}}=\text { Toluglendiamin } \\
& \frac{G_{2} \mathrm{H}_{2} \mathrm{~N}_{2} \Theta_{2}=\text { zwei Molecule Cyansäuro }}{\mathrm{G}_{8} \mathrm{H}_{12} \mathrm{~N}_{4} \theta_{2}=\text { Toluylenharnstoff. }} \\
& G_{7} \mathrm{H}_{10} \mathrm{~N}_{8} \\
& \boldsymbol{G} \mathrm{H} \boldsymbol{N} \\
& G_{8} H_{11} N_{3} \theta=\text { Toluylenharnstoff von Märkei. }
\end{aligned}
$$

Ueber die Umwandlung der fetten Säuren in die Alkohole der parallel stehenden Reihe; von Dr. Otto Veiel.

Bei der 0xydation der Felte, Galle und ähnlicher Körper erhält man flüchtige felle Säuren, und zwar in der Regel ein Gemenge von allen Gliedern der homologen Reihe, von der Caprinsäure $\epsilon_{10} H_{20} \Theta_{2}$ bis zur Ameisensäure $\mathrm{GH}_{2} \theta_{2}$. Es ist nun wahrscheinlich, dafs die niederen Glieder der Reihe durch Oxydation der höheren Glieder entstehen. Da sich jedes höherstehende Glied von dem vorhergehenden durch 